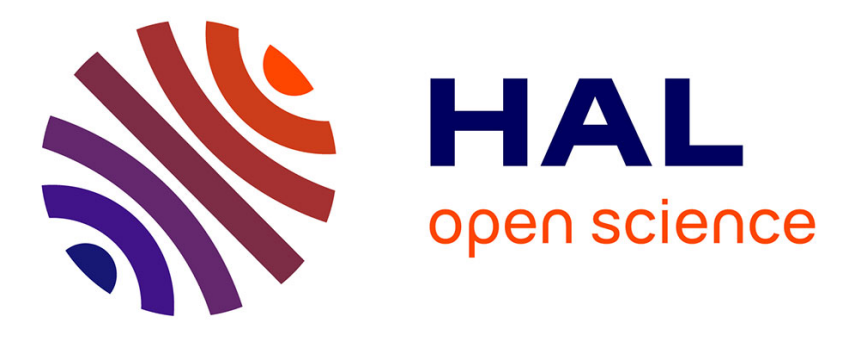

\title{
Tourist Spot Recommendation System with Image Selection Interface
}

Soh Masuko, Hayaki Kawata, Junichi Hoshino, Motoi Okuzono, Masahumi Muta

\section{- To cite this version:}

Soh Masuko, Hayaki Kawata, Junichi Hoshino, Motoi Okuzono, Masahumi Muta. Tourist Spot Recommendation System with Image Selection Interface. 16th International Conference on Entertainment Computing (ICEC), Sep 2017, Tsukuba City, Japan. pp.419-422, 10.1007/978-3-319-66715-7_53 . hal-01771304

\section{HAL Id: hal-01771304 https://hal.inria.fr/hal-01771304}

Submitted on 19 Apr 2018

HAL is a multi-disciplinary open access archive for the deposit and dissemination of scientific research documents, whether they are published or not. The documents may come from teaching and research institutions in France or abroad, or from public or private research centers.
L'archive ouverte pluridisciplinaire HAL, est destinée au dépôt et à la diffusion de documents scientifiques de niveau recherche, publiés ou non, émanant des établissements d'enseignement et de recherche français ou étrangers, des laboratoires publics ou privés. 


\title{
Tourist Spot Recommendation System with Image Selection Interface
}

\author{
Motoi Okuzono $^{1 *}$, Masahumi Muta ${ }^{2}$, \\ Soh Masuko ${ }^{2}$, Hayaki Kawata ${ }^{1}$ and Junichi Hoshino ${ }^{1}$ \\ ${ }^{1}$ University of Tsukuba, Graduate School of Systems and Information Engineering, \\ 1-1-1, Tennodai, Tsukuba-shi, Ibaraki, Japan \\ \{motoi,kawata.hayaki\}@entcomp.esys.tsukuba.ac.jp,jhoshino@esys.tsukuba.ac.jp \\ ${ }^{2}$ Rakuten, Inc., Rakuten Institute of Technology, \\ Rakuten Crimson House, 1-14-1, Tamagawa, Setagaya-ku, Tokyo, Japan \\ \{masafumi.muta, so.masuko\}@rakuten.com
}

\begin{abstract}
Nowadays, we often plan our travels by using tourism-related information abundantly available on the web. However, it is not simple to find useful information for your travel plans from enormous amount of information. This study, therefore, proposes a system that can make recommendations to you based on your preferences without you having to search information. Extracting the preferences of the users will be done simply by having images of their preferences selected by the users from the touristic images. The performance evaluation test on the system was also conducted.
\end{abstract}

Keywords: Recommendation system, User interface, Decision support.

\section{Introduction}

Along with the explosive diffusion of the Internet, enormous amout of touristic information has become available on the web, and we now often use the web information to plan our travels. However, such touristic information is provided randomly in various forms, sometiems created by municipalities, or in toursims information sites, blogs of individual persons as well as in reviews sites, and it is difficult for users to find useful information for their travel plans from the flood of touristic information.

In this article, we, therefore, propose a system that can recommend destinations of users' preferences to them that only requires a simple operation. Supposing that the travel dates are already set, and users are trying to make plans and itineraries, this system would help and simplifies the travel planning. In order to realize the simple operation, the interface was set as users only need to select tourism-related photos of their preferences repeatedly with their intuition. Also, in order to examine the preference-analysis method of this system, an evaluation test on the recommendation performance was conducted. 


\section{System Architecture}

\subsection{System Overview}

In this system, 16 image photos of different sightseeing destinations are displayed in the $4 \times 4$ boxes, and a user is to select 4 of them (Fig. 1). This process is to be repeated 10 times with different sets of image photos. This interface realizes the simplicity of extracting the users' preferences. The photos displayed corresponds the node of the preference model mentioned in the next section, and as images are selected, the parameters of the node increase. Moreover, as the image photos are displayed in the manner that it covers the entire categories the system deals, it can be expected that the users would discover their new preferences they were not aware of themselves. The kinds of photos to be displayed will be mentioned in the section of the database.

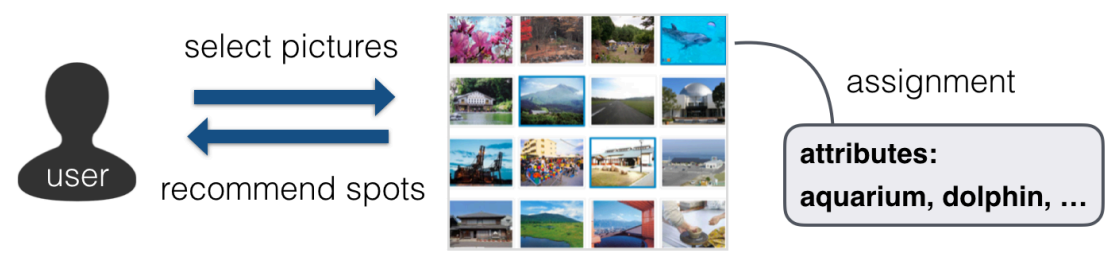

Fig. 1. User interaction on the proposal system.

\subsection{User Preference Model}

A preference model was created by defining user preferences in travels as:

- Categories of sightseeing spots they would like to visit

- Activities they would like to do at the destinations

The categories of sightseeing spots are set in a hierarchical structure such as "seeingnatural landscape-canyons", and the preference model was set in the same hierarchical structure as well. And by input, parameters that indicate how much they value each item are added to the model. An example of the actual preference model is shown in Fig. 2.

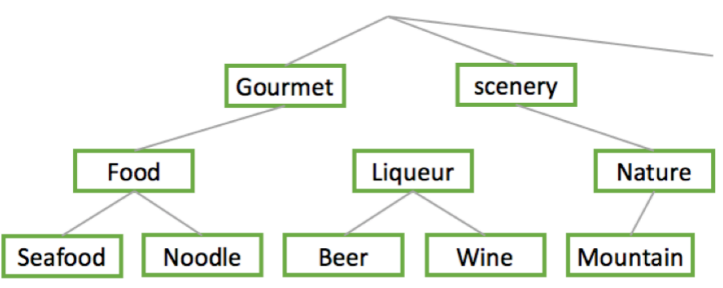

Fig. 2. User preference Model. 
When the evaluation value of a node $\mathrm{N} \mathrm{s}|N|$, and the node group that belongs to the node is $N x(x=1,2, \ldots, n)$, it would be:

$$
|N|=\sum_{i=0}^{n} N_{i}
$$

and, the evaluation value of the parent node directly affect the child node.

The characterization of the recommended tourist destinations would be determined by the categories and numbers of sightseeing spots of that destination. The number of the sightseeing spots is added with parameters to make it into the same model as the preference model, which would be normalized and expressed as the vector. The sightseeing spots and their categories, as well as the area they belong to were determined by referencing "Rakuten Travel Note" operated by Rakuten, Inc. As a result, the number of the sightseeing spots was 17,138 , the number of the categories was 125 and the number of recommendation candidate areas was 209. The photos displayed in the input interface were those of the sightseeing spots obtained, and the categories of the photos correspond those of the sightseeing spots.

\section{$3 \quad$ Evaluation Testing}

\subsection{Definition of Performance Index}

They are known for their accuracy as an index for information search system, and often used for the evaluation index for recommendation systems [2]. These are defined as follows:

$$
\text { Precision }=\frac{\left|T_{i}^{x} \cap i m L_{i}^{x}\right|}{i m L_{i}^{x}}
$$

$T_{i}^{x}$ is the group of items thde user preferred in recommendation candidates, and $\left|T_{i}^{x}\right|$ is the number of the item, $i m L_{i}^{x}$ is the map of $L_{i}^{x}$ mapping that indicates all the items in the map of $L_{i}^{x}$ mapping that indicates all the items in the recommendation list. The accuracy is defined as the percentage of the preferred items $b \in T_{i}^{x}$ in $T_{i}^{x}$ against the size of the recommendation list.

\subsection{Content of the Evaluation}

Following test was conducted, using the above-mentioned index:

1. To men and women from $22-26$ years of age, all of the 209 areas that were candidates of recommendation areas were displayed randomly along with the sightseeing spots of their preferences, and had them answer how attractive they found them in Likert scale from 1 to 5 (1: "not attractive at all" - 5: "very attractive").

2. The areas they answered as 4 and 5 in 1 are defined as their preferred items. 
3. Using the system, the top three recommendation outcomes were created, and it was assessed how many places of their preferences are actually recommended.

\subsection{Result of the Test}

Table 1 is the average of each user's knowledge and evaluation value of the 209 candidates for recommendation areas.

Table 1. The average of user's knowledge.

\begin{tabular}{cc}
\hline Unlike & Like \\
\hline 113.5 & 95.5 \\
\hline
\end{tabular}

Table 2 shows the results of the accuracy calculations.

Table 2. The system performance.

\begin{tabular}{c}
\hline Precision \\
\hline 0.556
\end{tabular}

While among the candidates sites, the preferred sites were slightly less than half, the accuracy of the recommendation outcomes turned out to be slightly more than half. Although it can be considered effective in certain degree, in terms of the accuracy, there is plenty of room for improvement.

\section{References}

1. Rakuten, Inc., Rakuten Travel - Get the best deals on Japanese Hotels and Ryokans, http://travel.rakuten.com, Accessed 10 Dec 2016.

2. Zhang, F.: Improving recommendation lists through neighbor diversification. In Intelligent Computing and Intelligent Systems, 2009. ICIS 2009. IEEE International Conference on, Vol. 3, pp. 222-225 (2009). 